\title{
THE NEW MATHEMATICS AND OCEANOGRAPHY BUILDING OF THE UNIVERSITY OF LIVERPOOL
}

\begin{abstract}
A
FEW weeks ago the University of Liverpool took over from the building contractors (Messrs. Gilbert-Ash, Ltd.) an almost completed Mathematics and Oceanography Building, the architects of which are Bryan and Norman Westwood and Partners, of London. The building, which will cost about $£ 260,000$, has three wings, one on each of three sides of a grasscovered central courtyard; the remaining side of the courtyard will, at some later time, be open to one of the pathways of what will then be the University Precinct.

The main wing is a gracious six-storeyed structure of glass, black concrete pillars, and white concrete panels of special design. On the flat roof there is a 'wood and glass' penthouse in which the transcendental verities may be contemplated in relative comfort. Below the building is a basement for the usual services, and farther below still there is the area boiler house.

On the ground floor of the main wing, which is well set back from the road, and which is approached along a covered pathway traversing the courtyard, there is a spacious white-walled, airy, bright, central hall, the floor of which is made of attractive grey green slate. On one of the walls of the hall there is a five-panel mural inspired by the users, designed by John McCarthy, and executed by him in red terossa ferrata. This mural represents, in various groups, the history and development of mathematics, and many
\end{abstract}

of the important branches of human activity in which pure and applied mathematics play, or have played, a significant part. In addition, the hall contains a tall black-concrete abstract mural designed and executed by Eric Peskett. Leading off the central hall there will be, when completed, the two principal lecture rooms of the new building. The rooms will be large enough to hold audiences of 110 and 145 , respectively, and they will be named after A. R. Forsyth and J. Proudman, the first professors of pure mathematics and applied mathematics of the University of Liverpool. Proudman was afterwards transferred to the University chair of oceanography, and did much to give the Department of that subject its high reputation; it is therefore a particularly happy arrangement whereby the Departments of Mathematics and Oceanography are now housed in the same building.

The first and second floors contain lecture rooms; the third floor contains more lecture rooms as well as the Sub-Department of Mathematical Statistics. The fourth floor contains private rooms for the applied mathematics staff, and the fifth floor has similar rooms for the pure mathematies staff, as well as rooms for research students.

At ground-floor level, at right-angles to the main block, there is a single-storey wing containing the Oceanography Laboratories; these are used for research and for instruction for honours under-

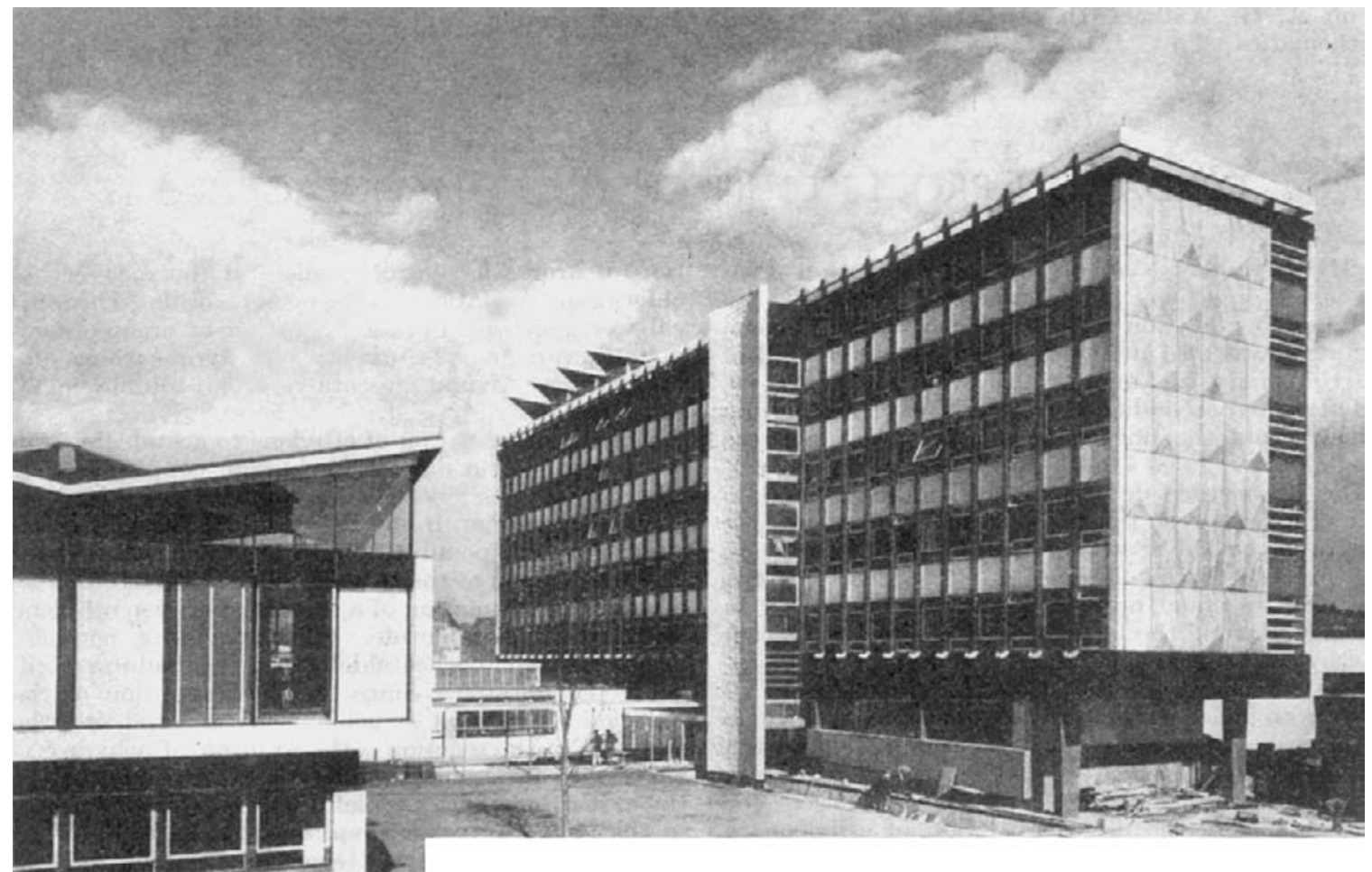

Fig. 1. New Building for Mathematics and Oceanography: the Central Court from Walnut Street 
graduates. There are four main laboratories, two for physical work and two for chemical. Other rooms, such as a spectrographic room, balance room, dark room, workshop and store, are provided for special purposes. The laboratory accommodation and equipment offer facilities, on the chemical side, for work on the analysis of sea-water, particularly of trace elements by spectrophotometric methods, and on the composition of marine sediments. On the physical side, there are facilities for developing and testing apparatus for measuring, for example, the temperature and electrical conductivity of sea-water, and the velocity and turbulent fluctuations of currents.

At right angles to the single-storey wing, parallel to the main wing, there is a two-storey block containing, at one end, staff rooms and a combined library and chartroom for oceanography. The remainder of this block is occupied by the SubDepartment of Numerical Analysis, which possesses, in addition to rooms for its staff, others which house an electronic computer and its ancillary equipment, and a mathematical laboratory.

The building was designed to cater for the estimated number of science and engineering students, and the appropriate staff, likely to study mathematics in one or more of its aspects, or oceanography, within a total student community of 5,000. The erection of the building had scarcely been begun, however, when, under the stimulus of revised estimates of national requirements, the University agreed to plan its development on the basis of an ultimate student population of about 7,000. Large as it appears to be, therefore, the building will probably not be big enough to meet the demands likely to be made on it towards the end of the 'sixties.

The research carried out by the staff and graduate students of the Department of Pure Mathematics (Prof. A. G. Walker), the Department of Applied Mathematics (Prof. L. Rosenhead), with its Sub-
Department of Mathematical Statistics (R. L. Plackett, reader in mathematical statistics), and its Sub-Department of Numerical Analysis (Dr. A. Young, reader in numerical analysis), and the Department of Oceanography (Prof. K. F. Bowden) covers a very wide range. The work that is going on in oceanography has been mentioned earlier; in pure mathematics research interests include classical analysis, group theory, algebraic and differential geometry and topology; and in applied mathematics work is being done on fluid motion, acoustics, quantum theory, nuclear physics, theoretical chemistry, astronomy, geophysics, numerical analysis and mathematical statistics.

The facilities of this well-co-ordinated group of teachers and research workers will be increaserl within the next few years when, with the aid of the grant recently promised by the University Grants Committee, an English Electric $K D F 9$ Computer will be obtained to replace the existing Dence of the Computer Laboratory, which was bought with funds provided by local industrialists and the University Council.

The University skyline at the top of Brownlow Hill is changing significantly-new buildings for physics, chemistry and veterinary science have been orected; still more buildings are going up for chemistry-and the foundations of engineering buildings as well as those of an extension of the Students' Union are now being laid. Within this complex of building activity the white-walled Mathematics and Oceanography Building stands out as something rather different and aloof; but the building will, we hope, serve as a university focus of mathematical thinking, teaching and research, and a centre from which mathematical service will flow to the University as a whole-as well as a place where important work on oceanography will be carried out.

\section{Rosenhead}

\section{OXIDATION PROCESSES IN CHEMICAL MANUFACTURE}

HE two-day symposium on "Oxidation Pro-
cesses in Chemical Manufacture" organized by
the London Section of the Society of Chemical
Industry, was held in the William Beveridge Hall of
the University of London during September 28-29,
and attracted an audience of some 250 scientists from
industry and the universities-with many overseas
members.
The remarkable development in industrial oxida-
tion processes over the past decade is perhaps best
illustrated by the fact that while six comparatively
new processes were discussed in some detail by the
speakers, an equal number were mentioned only in
passing. Among the latter were the direct oxidation
of ethylene to ethylene oxide, the oxidation of pro-
pylene to acrolein, the subsequent oxidation of
acrolein to glycerol, the direct oxidation of propylene
in the presence of ammonia to acrylonitrile, and the
production of hydrogen peroxide by the peroxidation
of isopropyl alcohol. The processes chosen for
discussion were the direct oxidation of ethylene to
acetaldehyde, the vapour phase oxidation of acetalde-
hyde to peracetic acid, the uses of hydrogen peroxide
in industrial oxidations with particular reference to
epoxide formation, recent developments in the oxida- tion of aromatic hydrocarbons and the recovery of chlorine by oxidation of hydrogen chloride. Theoretical work on liquid-phase oxidation of organic compounds, vapour-phase oxidation of hydrocarbons and liquid phase oxidation catalysed by soluble metal salts was also discussed.

The direct oxidation of ethylene to acetaldehyde in the presence of a palladium chloride-copper chloride catalyst was described by Dr. Smidt (Consortium für Elektrochemische Industrie G.m.b.H.) as a singlestage reaction possibly applicable to other olefines. The mechanism of the reaction in the case of ethylene involves the formation of a complex between ethylene and palladium chloride. The resulting complex decomposes to give acetaldehyde, the palladium metal being precipitated. Since the decomposition of the complex is inhibited by acids, it is suggested that the first step in the reaction is the addition of a hydroxyl ion to the complex-bound olefine. In the second stage the $\pi$ electron pair of the olefine passes over completely to the palladium with simultaneous migration of an hydride ion from carbon 1 to carbon 2. A double bond is then formed between carbon atom 1 and the oxygen of the hydroxyl group with expulsion of proton. On this hypothesis the oxygen required for the oxidation 